\title{
KHAT CHEWING AND SMOKING EFFECT ON ORAL MUCOSA: A CLINICAL STUDY
}

\author{
Essam Halboub ${ }^{1}$, Essam Dhaifullah ${ }^{2}$, Mahmoud Abdulhuq $^{1}$ \\ Damascus University, Faculty of Dentistry, Damascus, Syria: Department of Oral Medicine' ${ }^{1}$ Sana'a University, Faculty \\ of Dentistry, Sana'a, Yemen: Department of Periodontology ${ }^{2}$
}

\begin{abstract}
Summary: Khat (Catha Edulis Forskal) is widely cultivated in Yemen and East of Africa. The habit of chewing tender leaves and twigs of khat is deep-rooted in Yemen. Our study investigates the chronic khat chewing and smoking effect on oral mucosa. The sample $(n=79)$ consists of two main groups, khat chewers $(n=54)$ and control groups $(n=25)$. Khat chewers group is divided into 4 subgroups according to duration of khat chewing and smoking habit. The control group is divided into 2 subgroups according to smoking habit. Whitening with mild corrugation, frictional keratosis and frictional keratosis with mild or sever corrugation were the clinical findings. One hundred percent of clinical findings were present on buccal mucosa of chewing side of both smokers and non-smokers whatever the duration of khat chewing period. On the vestibular and mucobuccal fold mucosa, (100\% and $73.3 \%)$ and (60 \% and $43.7 \%$ ) of the khat chewers group had clinical findings on chewing side of smokers and non-smokers according to khat chewing duration respectively. There was clinical relationship between these lesions and khat chewing, but not smoking. Khat chewing causes oral white lesions on the chewing side and it is found that smoking, clinically, does not exacerbate such lesions.
\end{abstract}

Key words: Khat; Catha Edulis Forscal; Smoking; White lesion; Frictional keratosis

\section{Introduction}

Khat chewing is a deep-rooted habit in Yemen. It was exclusively adult males' habit (17), but it begins to spread among females $(4,15)$ and children (4). World Health Organization estimated that $70 \%$ to $90 \%$ of men, $30 \%$ to $50 \%$ of women and $25 \%$ of children in Yemen chew khat daily (23). In two separated studies Ali A estimated the prevalence of khat chewing habit in Yemen to be $60.5 \%$ and $61.12 \%$ respectively $(2,3)$.

According to individual authors' observations, khat chewing causes stomatitis that might be secondarily infected $(9,17,20)$. It also causes periodontitis, teeth discoloration and xerostomia $(9,17)$.

There are wide differences in the published epidemiological studies about the effect of khat chewing on oral cavity. Concerning it's dental effect, Hill CM and Gibson A (1987) claimed reduced dental caries among khat chewers (13). Others concluded increased dental carie, especially the cervical ones, teeth staining and attrition in addition to their mobility $(5,22)$. Regarding it's effect on periodontium, it causes gingivitis, periodontitis, periodontal pocket formation and gingival recession $(2,5,22)$. On contrary, other authors proved positive effects of khat chewing, namely less loss of clinical attachment and less pocket depth on the chewing side compared to non-chewing side $(13,21)$ and less plaque and calculus indices among khat chewers compared to non-chewers (14).

The aim of this study is to investigate, clinically, the effect of chronic khat chewing on oral mucosae (other than gingiva) and to see if cigarette smoking has additive effect.

\section{Material and method}

The study sample consists of 79 Yemeni subjects divided into two main groups, chronic khat chewers $(n=54)$ and control $(n=25)$. The chronocity of khat chewing was defined to be not less than 5 years since starting the habit, not less than 5 days per week and not less than 4 hours per day. The selection criteria of the subjects are male (due to traditional difficulties in finding female sample), systemic diseases-free, no chronic drugs or alcohol users, no shamma (smokeless tobacco) users, do not complain oral mucosal symptoms or use removal dental appliance, For khat chewers, they should chew khat on one side only.

The khat chewers group was subdivided according to chewing duration and smoking into six subgroups, Khat chewers for 5-15 years and non-smokers $(n=16$, mean age $=27.1)$, Khat chewers for 5-15 years and smokers $(n=15$, mean age $=28.5$ ), Khat chewers for more than 15 years and non-smokers $(n=10$, mean age $=37.6)$, Khat chewers for more than 15 years and smokers $(n=13$, mean age $=36.8)$. 
The control group was subdivided according to smoking habit into two subgroups: Non-smokers $(n=15$, mean age $=31.9)$, Smokers $(n=10$, mean age $=28.2)$.

A comprehensive oral mucosal clinical examination (8, 10) was done by two examiners for both sides (chewing and non-chewing sides regarding khat chewers group and right and left sides regarding control group). The following were the clinical findings the two examiners agreed on and consequently recorded.

1. Whitening: a pale white mucosal color without rough surface on palpation. This is the first stage of keratosis (7).

2. Frictional keratosis: a patch or dens white plaque of rough surface on palpation (7).

3. Mild corrugation: mucosal foldings that disappear on gentle stretching while the subject is relaxed.

4. Sever corrugation: mucosal foldings that do not disappear on gentle stretching while the subject is relaxed.

Statistical analysis was performed by using the SPSS computer program. Differences were considered statistically significant at $\mathrm{p}<0.05$ by using chi-squared $\left(\mathrm{x}^{2}\right)$ test.

\section{Results}

The mean age of the subjects was 32.35 years (range 18-71 years). The clinical findings, whatever their types, confined primarily on buccal mucosae, alveolar and mucobuccal fold mucosae and to lesser extent on retromolar pad mucosae. There were no khat chewing-specific findings on the tongue, palate or flour of the mouth.

The percentages of clinical findings on the buccal mucosae of the control subgroups, non-smokers and smokers, were $0 \%$ and $10 \%$ respectively and representing one case of whitening. On contrary the percentages of the clinical findings on the buccal mucosae of the chewing sides of khat chewers subgroups, non-smokers and smokers, were $100 \%$ and $100 \%$ respectively and $15 \%$ and $28.6 \%$ respectively on the non-chewing sides.

The types of these clinical findings on the chewing sides of non-smokers varied according to the duration of khat chewing habit, less or more than 15 years, between whitening (31.3\% and $10 \%$ respectively), whitening with mild corrugation (25\% and $50 \%$ respectively) (Fig. 1), frictional keratosis (25\% and $10 \%$ respectively) (Fig. 2) and frictional keratosis with mild corrugation ( $18.8 \%$ and $30 \%$ respectively). These findings were less varied on the non-chewing sides of the same subgroups where only $18.8 \%$ and $0 \%$ respectively of whitening and $0 \%$ and $10 \%$ respectively of whitening with mild corrugation were present.

Similarly, the types of the clinical findings on the chewing sides of the smokers varied according to the duration of khat chewing habit, less or more than 15 years, between whitening with mild corrugation $(20 \%$ and $23.1 \%$ respectively), frictional keratosis ( $13.3 \%$ and $7.7 \%$ respectively), frictional keratosis with mild corrugation (66.7 \% and $46.2 \%$ respectively) and frictional keratosis with sever corrugation ( $0 \%$ and $23.1 \%$ respectively). These findings were less va- ried on the non-chewing sides of the same subgroups where only $33.3 \%$ and $7.7 \%$ respectively of whitening and $0 \%$ and $7.7 \%$ respectively of frictional keratosis were present.

There was no statistically significant difference when comparing the frequency of the clinical findings between right and left sides of the control subgroups, smokers and non-smokers, ( $p>0.05)$ while the difference was statistically significant between chewing and non-chewing sides of khat chewers subgroups $(p=0.000-0.002)$. There was no statistically significant difference, regarding to frequency of the clinical findings, when comparing smokers and nonsmokers of different subgroups and also when comparing khat chewing duration, less or more than 15 years $(p>0.05)$. The statistical difference was highly significant $(p=0.000)$ when comparing chewing sides of khat chewers with both sides of control group whatever the smoking habit was. On the other hand, no statistical difference was found between non-chewing sides of khat chewers and both sides of control group $(\mathrm{p}>0.05)$ whatever the smoking habit was.

The second main site, even to less extent, that the khat chewing-specific findings were confined to was the vestibular and mucobuccal fold mucosae where (100\% and $73.3 \%$ ) and $(60 \%$ and $43.7 \%)$ of the khat chewers had clinical findings on chewing side of smokers and non-smokers according to khat chewing duration respectively whereas only $6.7 \%$ (one case) of clinical findings were present on non-chewing side of smoker and khat chewer for less than 15 years. The statistical differences that were found when comparing the frequency of clinical findings on buccal mucosae of different subgroups (according to different variables) equally applied to the frequency of clinical findings on vestibular and mucobuccal fold mucosae.

A $75.9 \%$ of khat chewers group were chewing khat on the left side.

\section{Discussion}

Chronic khat chewing causes white lesions that range between whitening, as the least effect seen clinically, to frictional keratosis with sever corrugation, as the worst effect seen clinically. These lesions confined primarily to buccal mucosa and to less extent to vestibular and mucobuccal fold mucosae. The way of khat chewing, accumulation of khat bolus against buccal and vestibular mucosae, illustrates why the clinical findings are nearly exclusively confined to these mucosae and this is in agreement with Gorsky $\mathrm{M}$ et al (11). There is no statistical difference between smokers and non-smokers regarding presence of such lesions as Gorsky $\mathrm{M}$ et al concluded (11). The statistical differences between chewing and non chewing sides of either smokers or non smokers and the low or absence of clinical findings in the control group, smokers or non smokers equally, confirm such conclusion. Such lesions could be attributed to the continuous friction of khat against mucosae during khat chewing sessions. The chemical composition of khat might play a role. This explanation is in agreement with previous 


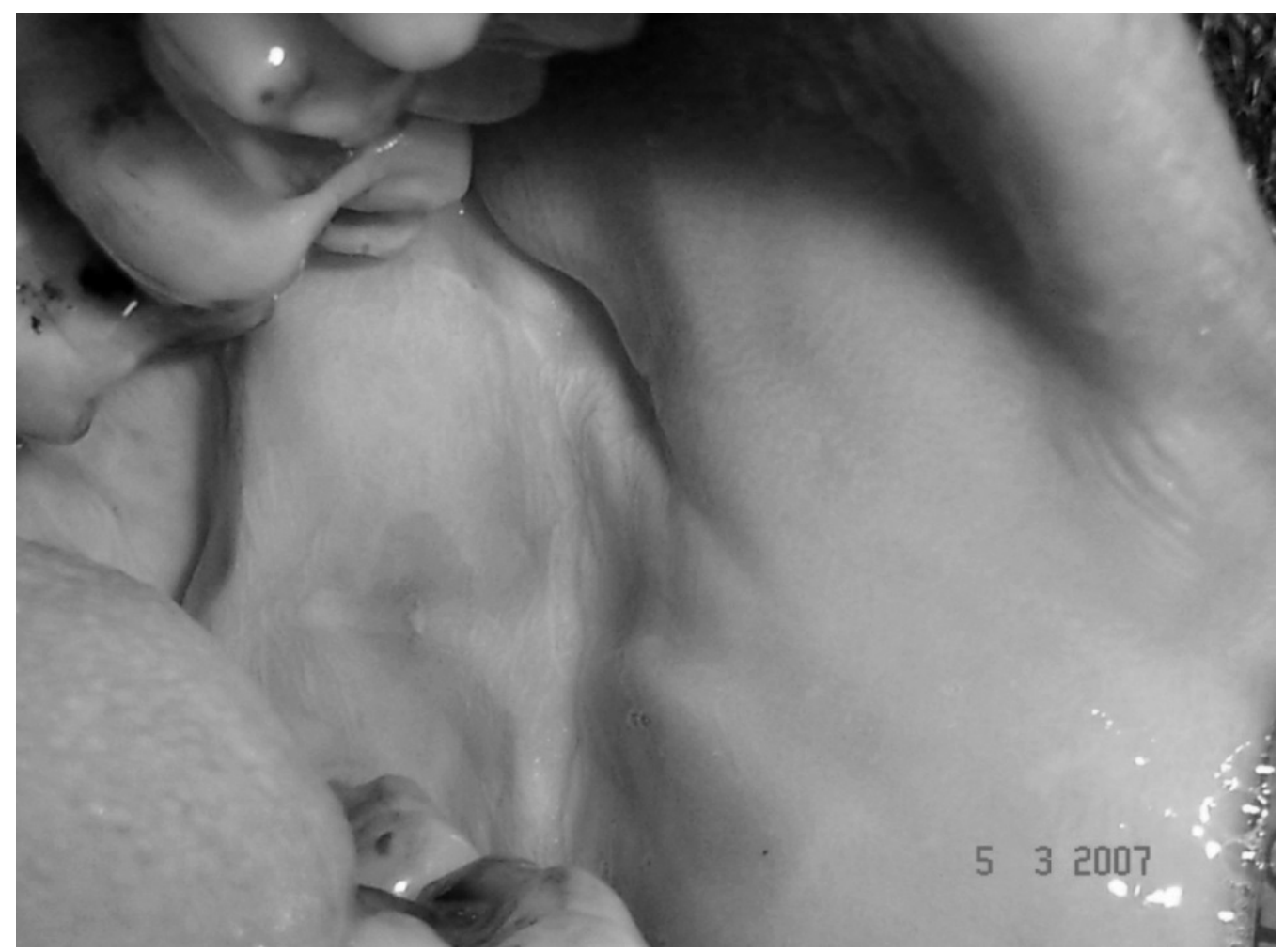

Fig. 1: Whitening with mild corrugation of the buccal mucosa on the khat chewing side.

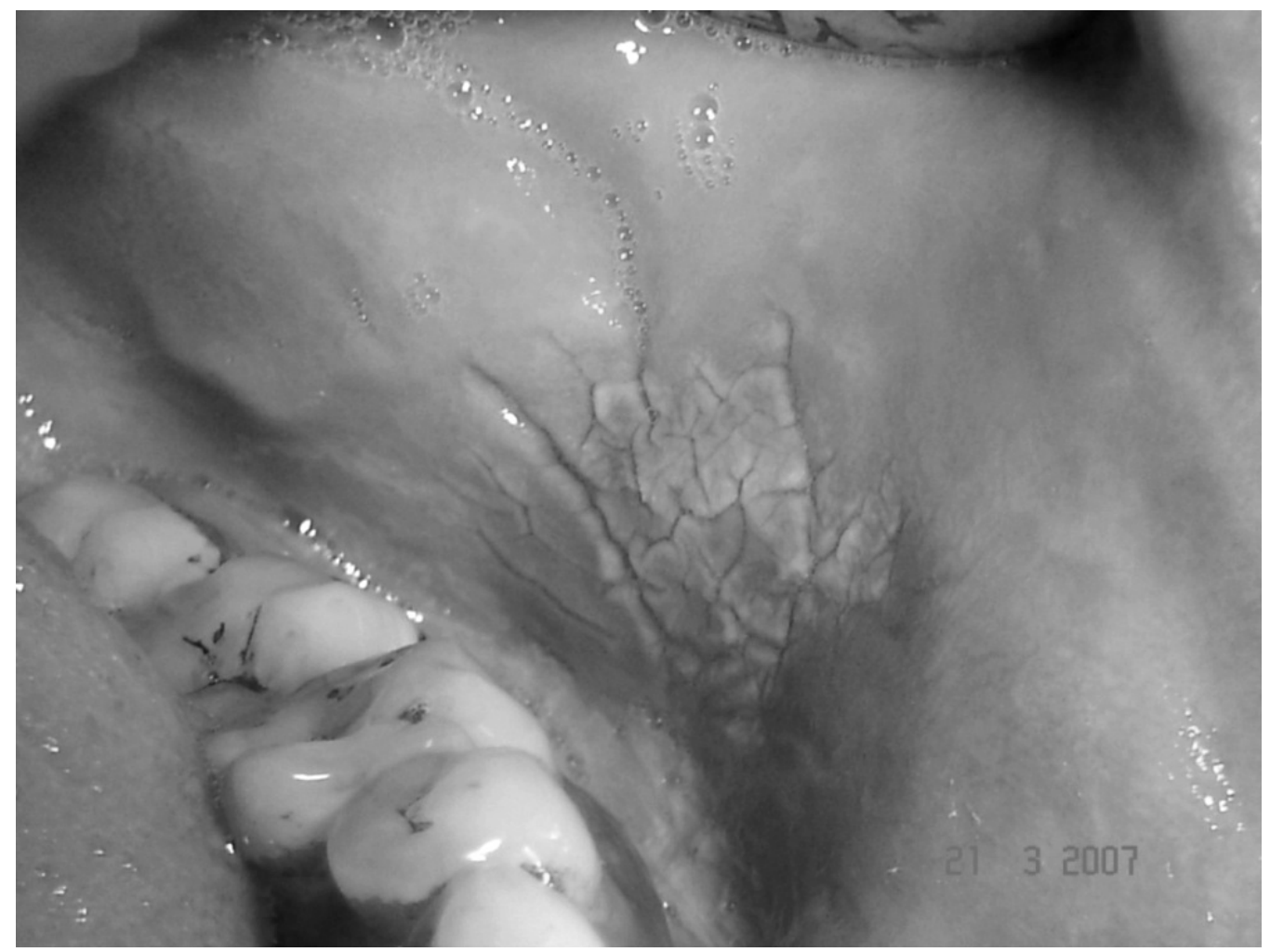

Fig. 2: Frictional keratosis of the buccal, vestibular and mucobuccal fold mucosae on the khat chewing side. 
studies $(2,3,5,11,22)$. These lesions intensify with increased duration and frequency of khat chewing (3).

In this study we aimed to evaluate the chronic khat chewing effect on oral mucosa and not the prevalence of khat-induced oral lesions as other authors did $(2,3,13)$. That is why the percentages of the frequency of the clinical findings in this study were high compared to $22.4 \%$ (3), $23.5 \%$ (2) and 50\% (13) in the mentioned studies. Other non-epidemiological studies revealed close percentages to ours, namely $77 \%$ (22) and $83 \%$ (11). Regarding the types of clinical findings, this study disagrees with other studies that diagnosed them as khat related leucoplakia (11) or true leucoplakia $(2,3)$. World health organization defined leucoplakia as a white lesion that can not be diagnosed clinically or histologically as any other lesion and can not be attributed to a well defined cause (6).

The corrugation can be attributed to continuous stretching of muscular and collagen fibers during khat chewing sessions. It is found that khat chewing causes facial asymmetry due to hyperplasia of masseter muscle on the chewing side $(5,22)$.

Al-Hebshi NN and Skaug N (1) mentioned that $67 \%$ of khat chewers chew on the left side. This is close to the result of this study, $75.9 \%$, and that might be explained as habitual.

\section{Conclusion}

Chronic khat chewing causes oral white lesions that confined to the chewing side of the mouth and it is found that smoking, clinically, does not exacerbate such lesions.

\section{References}

1. Al-Hebshi NN, Skaug N. Effect of Khat Chewing on 14 selected periodontal bacteria in sub- and supragingival plaque of a young male population. Oral Microbiol Immunol 2005; 20(3): 141-6.

2. Ali A. Oral disease related to Qat chewing in Yemen. Damascus University Journal For Health Science 2003; 19(3): 143-59. Arabic
3. Ali AA, Al-Sharabi AK, Aguirre JM, Nahas R. A Study of 342 oral keratotic white lesions induced by Qat chewing among 2500 Yemeni. J Oral Pathol Med 2004; 33(6): $368-72$.

4. Al-Motarreb A, Baker K, Broadley KJ. Khat: pharmacological and medical aspects and its social use in Yemen. Phytother Res 2002; 16(5): 403-13.

5. Alsharabi AK. Oral and para-oral lesions caused by takhzeen Al-Qat (dissertation). Khartoum, Sudan: Khartoum University, 2002.

6. Barnes L, Eveson JW, Reichart P, Sidransky D. World health organization classification of tumours. Pathology and genetics of head and neck tumours. World health organization classification of tumours. Series eds. Barnes L, Eveson JW, Reichart, P, et al. 2005, IARCPress: Lyon.

7. Bhattacharyya I, Cohen DM, Silverman, SJ. Red and white lesions of the oral mucosa. In: Greenberg, MS and Click, M, eds. Burkit's oral medicine diagnosis and treatment. Hamilton, Ontario: BC Decker Inc, 2003:85-125.

8. Click M, Siegal MA, Brightman VJ. Evaluation of the dental patient: diagnosis and medical risk assessment. In: Greenberg MS, Click M, eds. Burkit's oral medicine diagnosis and treatment. Hamilton, Ontario: BC Decker Inc 2003: 5-35.

9. Dhaifalah I, Santavy J. Khat Habit and Its Health Effect. A Natura Amphetamine, Biomed Pap Med Fac Univ Palacky Olomouc, Czech Repub 2004; 148(1): 11-15.

10. Eversole LR, Silverman SJ. Physical examination of the head and neck. In: Silverman SJ, Eversole, ER, Truelove EL. Essentials oral medicine, eds. Hamilton, Ontario: BC Decker Inc, 2001: 6-26.

11. Gorsky M, Epstein JB, Levi H, Yarom N. Oral white lesions associated with chewing khat. Tobacco induced diseases 2004; 2(3): 145-50.

12. Halbach H. Medical aspects of the chewing of khat leaves. Bull World Health Organ 1972; 47(1): 21-29.

13. Hill CM, Gibson A. The oral and dental effects of Q'at chewing. Oral Surg Oral Med Oral Pathol 1987; 63(4): 433-6.

14. Jorgensen E, Kaimenyi JT. The status of periodontal health and oral hygiene of Miraa (Catha Edulis) Chewers. East Afr Med J 1990. 67(8): 585-90.

15. Kandela P. Women's rights, A Tourist boom, and the power of khat in Yemen. Lancet 2000. 355 (9213): 1437.

16. Kennedy JG. The flower of the paradise: The institutionalized use of the drug Qat in north Yemen. Dodrecht: D. Reidel Publications, 1987: 98-100.

17. Kennedy JG, Teague J, Rokaw W, and Cooney, E. A Medical evaluation of the use of Qat in north Yemen. Soc Sci Med, 1983. 17(12): 783-93.

18. Kerr DA, Ash MM, Millard HD. Oral diagnosis. 6th ed. ST. Missouri: The C.V Mosby Company, 1983

19. Langalis RP, Bricker SL, Cottone JM, Baker BR. Oral diagnosis, oral medicine and treatment planning. Philadelphia: W. B. Saunders Company, 1984:390

20. Luqman W, Danowski TS. The use of khat (Catha Edulis) in Yemen. Social and medical observations. Ann Med, 1976. 85(2): 246-9.

21. Mengel R, Eigenbrodt M, Schunemann T, Flores-de-Jacoby L. Periodontal status of a subject sample of Yemen. J Clin Periodontol 1996; 23(5):437-43.

22. Shuga-Al-Din HM. Effects of Qat chewing on periodontal health of adults in Sana'a, Yemen (dissertation). Khartoum, Sudan, Khartoum University. 2006.

23. World health organization, country cooperation strategy for world health organization and the republic of Yemen 2002-2007. Republic of Yemen. 2006, W.H.O, regional office for eastern Mediterranean, Cairo. Document EM/ARD/ 003/E/R.

\section{Corresponding author:}

Essam Dhaifullah, Department of Periodontology, Dental Faculty, Sana'a University, Sana'a, Yemen, PO Box 1247; e-mail: dhaifullahe@yahoo.co.uk 